\title{
Pediatric post-transplant lymphoproliferative disorder identified on random gastrointestinal biopsies shows non-mass-forming PTLD with clonal plasma cells: report of 2 cases
}

\author{
H. Tariq ${ }^{1}$ P. Dileep Menon ${ }^{1} \cdot$ R. Alkhateb ${ }^{1} \cdot$ C. Forker $^{2} \cdot$ K. Holder $^{1} \cdot$ A. Nazarullah ${ }^{1}$ (D) \\ Received: 19 April 2020 / Accepted: 4 June 2020 / Published online: 12 June 2020 \\ (C) Springer-Verlag GmbH Germany, part of Springer Nature 2020
}

\begin{abstract}
EBV-related lymphoproliferations in post-transplant settings range from non-destructive hyperplasia to polymorphic posttransplant lymphoproliferative disorder (PTLD) to overt lymphoma. Here we present two unusual cases of pediatric nonmass-forming gastrointestinal (GI) PTLDs with mixed pathologic features of non-destructive and polymorphic categories. Both patients were EBV naïve and presented within 1 year of transplant with non-specific gastrointestinal symptoms (diarrhea, abdominal pain, and food intolerance) with hypoalbuminemia, cytopenia, and EBV viremia. No mass lesions were found on imaging and endoscopy. Random GI biopsies showed a non-mass-forming, but polymorphic-appearing lymphoid infiltrate with EBV positivity, monotypic plasma cells, and clonal B cells. Cyclophosphamide, steroids, and rituximab treatment had good clinical response in all cases, including one case which had poor response initially with rituximab alone. Based on these cases, we conclude that GI PTLD in children can present with vague abdominal symptoms, cytopenia, and hypoalbuminemia, and can be non-mass-forming and non-destructive. A high level of suspicion with random GI biopsies and clinicopathologic and laboratory correlation are required. Since these patients have no mass lesions, evaluating symptomatic relief, EBV viral load, improvement in cytopenia(s), serum albumin levels, and/or resolution of other systemic symptoms may be needed to monitor response to therapy.
\end{abstract}

Keywords Pediatric $\cdot$ PTLD $\cdot$ Transplant $\cdot$ Gastrointestinal $\cdot$ Polymorphic

\section{Introduction}

Post-transplant lymphoproliferative disorders (PTLD) are lymphocytic and/or plasmacytic proliferations that develop as a consequence of immunosuppression in a recipient of a solid organ or stem cell allograft. This heterogeneous group of disorders range from non-destructive hyperplasia to polymorphic PTLD to overt lymphoma [1]. The current WHO classification of tumors of hematopoietic and lymphoid tissues classifies PTLD into non-destructive PTLD, polymorphic PTLD, monomorphic PTLD, and classic Hodgkin lymphoma PTLD based on morphology (the absence or presence and degree

A. Nazarullah

Nazarullah@uthscsa.edu

1 Department of Pathology and Laboratory Medicine, University of Texas Health, 7703 Floyd Curl Dr, San Antonio, TX 78229, USA

2 Pathology and Cytology Laboratories, 290 Big Run Rd, Lexington, KY 40503, USA of architectural distortion), cellular composition, immunophenotype, and clonality of the cells constituting the lesion. Non-destructive PTLDs typically arise as massforming lesions that do not cause architectural effacement of the involved tissue and consist of polyclonal B cells and/or plasma cells with admixed T cells. Majority of these cases are EBV-positive and are negative for clonally rearranged immunoglobulin (IG) genes. Polymorphic PTLDs present as mass lesions that cause architectural effacement of the involved tissue and are composed of a heterogeneous population of immunoblasts, plasma cells, and small and intermediate sized lymphocytes, with or without light chain restriction, and do not fulfill the criteria of any of the recognized types of lymphoma described in immunocompetent hosts [2]. Most cases of polymorphic PTLD are EBV-positive and demonstrate clonally rearranged IG genes [2,3].

Here we present two unusual cases of pediatric non-massforming gastrointestinal (GI) PTLDs with pathologic features overlapping between non-destructive and polymorphic PTLD 
categories. Both cases were identified on random GI biopsies that were taken due to non-specific gastrointestinal symptoms (i.e., diarrhea, abdominal pain, and food intolerance) and also had hypoalbuminemia, cytopenia(s), and EBV viremia.

\section{Materials and methods}

An electronic search for pediatric PTLDs with GI involvement yielded two cases. Chart review for clinical and imaging findings was performed. Immunohistochemical stains and EBER in situ hybridization were performed on formalin-fixed paraffin-embedded tissue. Molecular studies for IGH and/or IGK gene rearrangements with BIOMED primers were performed in both cases. Flow cytometry on ascitic fluid was performed on one case.

\section{Results}

\section{Case 1}

The patient is an 18-month-old EBV naïve Hispanic girl who presented with severe diarrhea 5 months post liver transplant for biliary atresia, maintained on Prograf for immunosuppression. Laboratory studies showed new onset pancytopeniaWBCs $2.41 \mathrm{~K} / \mathrm{mcL}(6.00-13.50 \mathrm{~K} / \mathrm{mcL})$, RBCs $3.04 \mathrm{M} / \mathrm{mcL}$ (3.97-5.01 M/mcL), hemoglobin $8.5 \mathrm{~g} / \mathrm{dL}(10.2-12.7 \mathrm{~g} / \mathrm{dL})$, platelets $128 \mathrm{~K} / \mathrm{mcL}$ (206-459 K/mcL); hypoalbuminemiaserum albumin $2.9 \mathrm{~g} / \mathrm{dL}(3.2-5.0 \mathrm{~g} / \mathrm{dL})$; and EBV viremia2529 copies $/ \mathrm{mL}(<200$ copies $/ \mathrm{mL})$. CT scans of the chest, abdomen, pelvis, and neck failed to reveal any concerning masses. Colonoscopy and upper GI endoscopy exams were normal and did not reveal any suspicious mass lesions or ulcers. Random biopsies of the colon, duodenum, and stomach were obtained to evaluate for the cause of diarrhea.

A random duodenal biopsy showed a non-destructive atypical lymphoid aggregate in the lamina propria composed of small and intermediate sized lymphoid cells, immunoblasts, and plasma cells (Fig. 1a, b). No lymphoepithelial lesions were seen; however, there was focal villous blunting. Immunohistochemistry showed numerous small, intermediate, and large CD20 positive B cells with admixed small CD3 positive T cells (Fig. 1c, d). EBER ISH stain showed many positive small and intermediate sized cells within and around the aggregate (Fig. 1f). Kappa and Lambda IHC stains showed polytypic plasma cells in most of the submucosal plasma cells but showed kappa light chain restriction in the plasma cells at the periphery of the lymphoid aggregate (Fig. 1g, h). Rare large atypical CD30 positive cells were also seen (Fig. 1e). No tissue was procured for flow cytometry. Molecular studies were positive for clonal rearrangement of the IGH gene in a polyclonal background. Subsequent bone marrow biopsy showed no evidence of PTLD. Following a diagnosis of PTLD, the patient was treated with reduction of immunosuppression and six cycles of rituximab, cyclophosphamide, and steroids (protocol ANHL0221) that resulted in resolution of pancytopenia, hypoalbuminemia, EBV viremia, and diarrhea. She remains asymptomatic and clinically stable 20 months following the diagnosis of PTLD with detectable, but non-quantifiable EBV levels.

\section{Case 2}

A 23-month-old EBV naïve Hispanic boy presented with diarrhea, weight loss, ascites, and lethargy 4 months post liver transplant for biliary atresia. He was maintained on Prograf for immunosuppression. Laboratory studies showed new onset pancytopenia-WBCs $2.16 \mathrm{~K} / \mathrm{mcL}(6.00-13.50 \mathrm{~K} / \mathrm{mcL})$, RBCs $2.80 \mathrm{M} / \mathrm{mcL}$ (3.97-5.01 M/mcL), hemoglobin $7.3 \mathrm{~g} /$ $\mathrm{dL}(10.2-12.7 \mathrm{~g} / \mathrm{dL})$, platelets $81 \mathrm{~K} / \mathrm{mcL}(206-459 \mathrm{~K} / \mathrm{mcL})$; hypoalbuminemia - serum albumin $2.4 \mathrm{~g} / \mathrm{dL}(3.2-5.0 \mathrm{~g} / \mathrm{dL})$; and EBV viremia-722,406 copies $/ \mathrm{mL}(<200$ copies $/ \mathrm{mL})$. Imaging, colonoscopy, and upper GI endoscopy were negative for mass lesions or suspicious findings similar to the first case. Random biopsies of the colon, duodenum, and stomach were obtained to evaluate for the cause of GI distress.

A random duodenal biopsy showed a small infiltrate consisting of small to medium mature lymphocytes, immunoblasts, plasma cells, histiocytes, and occasional eosinophils causing mild architectural distortion (Fig. 2a-b). CD20 highlighted increased numbers of polymorphic appearing $\mathrm{B}$ cells in a background of CD3+ T cells (Fig. 2c, d). CD30 positivity was observed in a few large cells (Fig. 2e). EBV by EBER ISH was positive in several small, medium, and large lymphocytes in this infiltrate (Fig. 2f). Immunohistochemistry for Kappa and Lambda could not be performed due to lack of sufficient tissue; however, flow cytometry on the ascitic fluid revealed a small abnormal lambdarestricted CD138+ plasma cell population (Fig. 2g, h). Molecular studies were positive for clonal rearrangement of the IGK gene in a polyclonal background. No clonal IGH gene rearrangement was detected. Subsequent bone marrow biopsy also showed involvement by PTLD and monotypic plasma cells. Clonal IGH and IGK gene rearrangements were detected in the bone marrow; however, the clonal IGK peak was different from that detected in the duodenum biopsy. After an incomplete clinical response to reduction of immunosuppression and rituximab alone for a month, the patient was treated with six cycles of rituximab in combination with cyclophosphamide and steroids (protocol ANHL0221) that resulted in resolution of anemia, leukopenia, hypoalbuminemia, EBV viremia, and diarrhea. He remains asymptomatic and clinically stable 22 months since the diagnosis with undetectable EBV levels. 

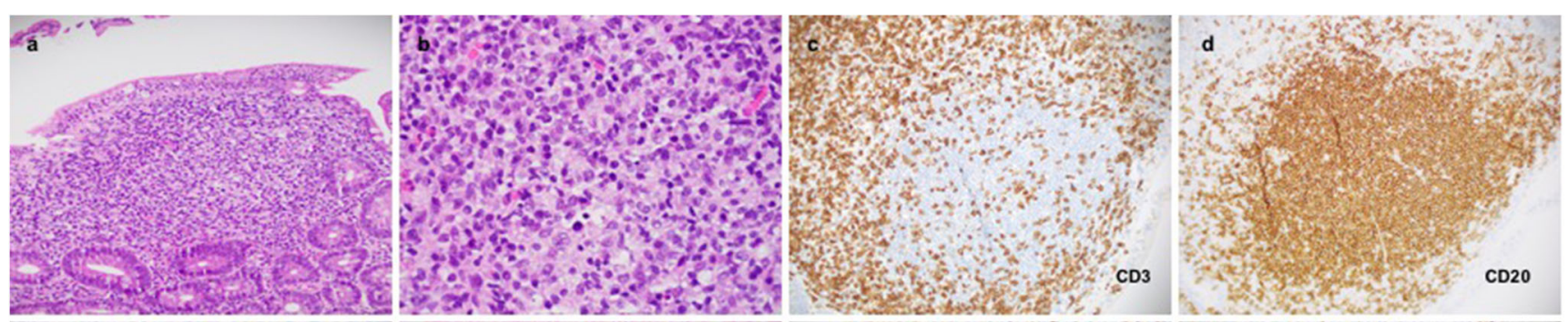
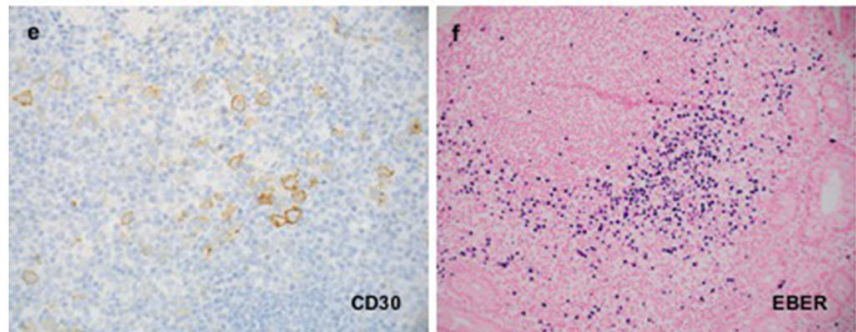

Fig. 1 Histopathologic findings in Case 1. a Low power view showing an atypical lymphoid infiltrate in the duodenal mucosa $(H \& E$ stain, $\times 10)$. b Higher power shows polymorphic morphology of the lymphoid cells with mixture of small, intermediate, and larger lymphocytes with admixed immunoblasts, histiocytes, and plasma cells $(H \& E$ stain, $\times 60)$. The

\section{Summarized features of 2 cases}

Both children were under 2 years old, EBV naïve, and presented within 1 year of transplant with non-specific abdominal symptoms (diarrhea in 2 of 2 cases and ascites, lethargy, and weight loss in 1 of 2 cases). Clinical findings included cytopenia(s) ( 2 of 2 cases), hypoalbuminemia ( 2 of 2 cases), and EBV viremia ( 2 of 2 cases). Radiologic imaging studies and upper and lower GI endoscopies did not reveal any mass lesions. A focal non-destructive polymorphic lymphoid infiltrate was

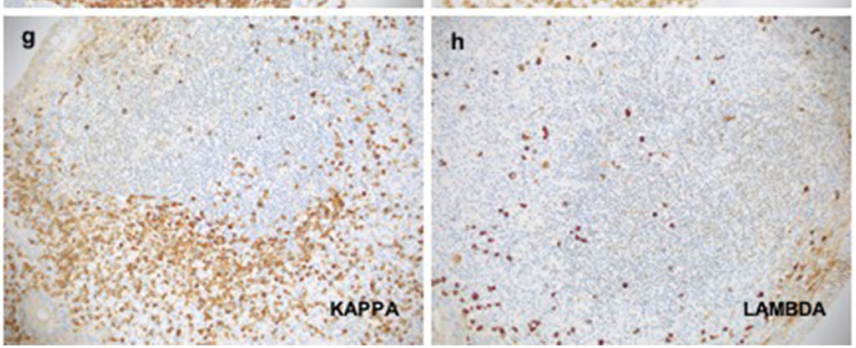

lymphocytes are predominantly CD20+ B cells (d) admixed with fewer CD3+ T cells $(\mathbf{c})$. e CD30 stain highlights scattered immunoblasts. f Numerous EBV-positive cells are detected on EBER ISH. $\mathbf{g}$ The plasma cells appear monotypic for kappa light chain. h Rare scattered lambda light chain expressing plasma cells are seen

identified on random GI biopsies. Both cases showed a polymorphic lymphoid infiltrate admixed with plasma cells and many EBV-positive cells. EBV-positive cells within both lesions were present in significant numbers (>30/high power field) and were clearly greater than that expected in latent EBV infections. Plasma cells in the GI biopsy were light chain restricted by IHC in one case and the other case showed involvement of ascitic fluid and bone marrow with light chain restricted plasma cells detected by flow cytometry. Treatment with cyclophosphamide, steroids, and rituximab had good
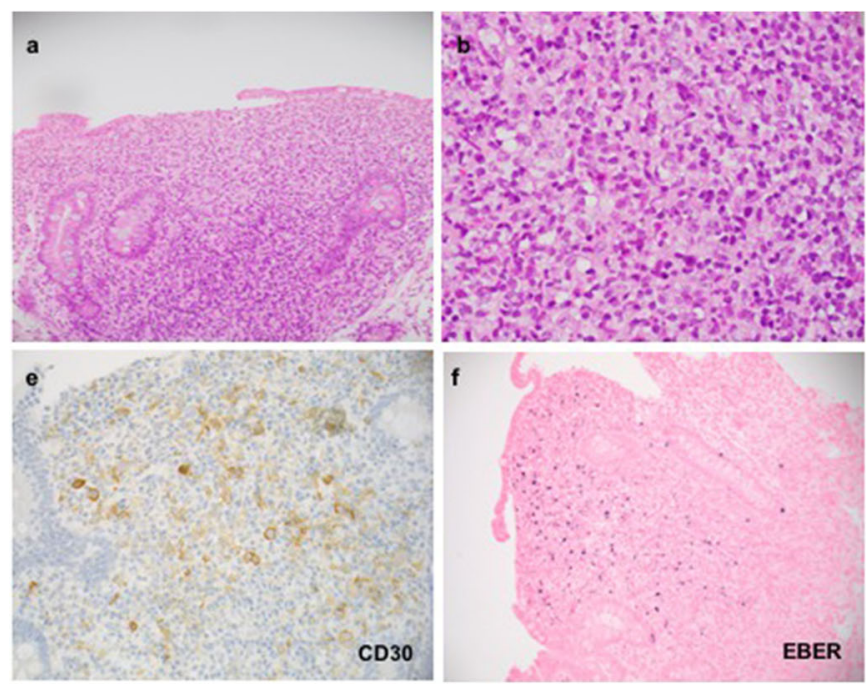

Fig. 2 Histopathologic findings in Case 2. a An atypical lymphoid infiltrate is noted in the duodenal mucosa on low power (H\&E stain, $\times$ 10). b Higher power shows polymorphic lymphoid infiltrate with mixture of small, intermediate and larger lymphocytes with admixed immunoblasts and plasma cells $(H \& E$ stain, $\times 60)$; The lymphocytes are

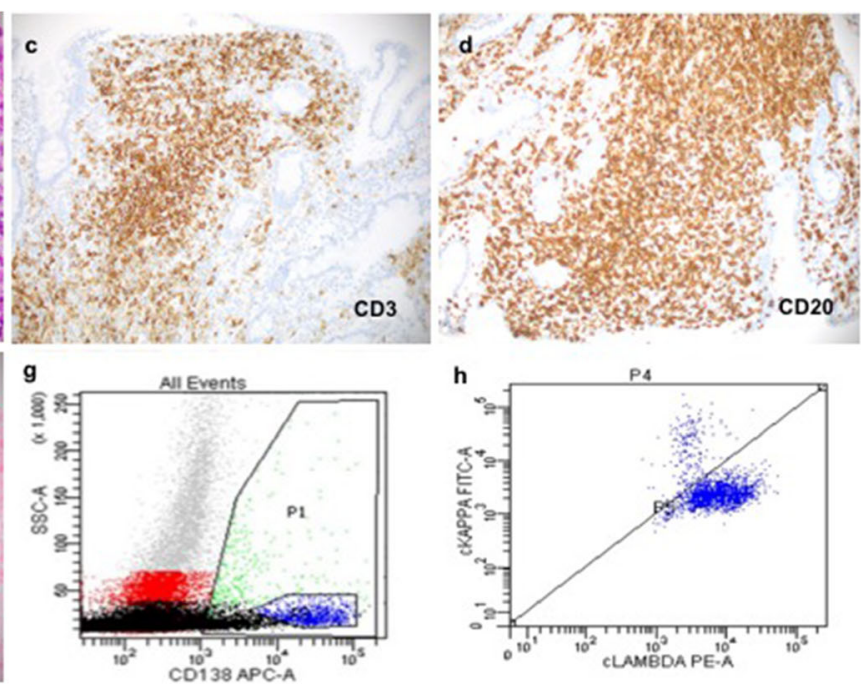

a mixture of $\mathrm{CD} 3+\mathrm{T}$ cells $(\mathbf{c})$ and $\mathrm{CD} 20+\mathrm{B}$ cells $(\mathbf{d})$. e CD30 stain highlights scattered immunoblasts. f Numerous EBV-positive cells are detected on EBER ISH. g Flow cytometry on ascitic fluid detects increased CD138 positive plasma cells. h Plasma cells appear to be lambda light chain restricted by flow cytometry 
Table 1 Summary of findings in the two cases of pediatric GI PTLD

\begin{tabular}{lll}
\hline & Case 1 & Case 2 \\
\hline Age and ethnicity & 18 months, Hispanic & 23 months, Hispanic \\
Transplant history & Liver transplant for biliary atresia & Liver transplant for biliary atresia \\
Clinical findings & Diarrhea, low albumin, pancytopenia & Diarrhea, ascites, low albumin, pancytopenia \\
Serum EBV & 2529 copies/mL & 722,406 copies $/ \mathrm{mL}$ \\
Endoscopic findings & No lesions & No lesions \\
Site of PTLD & Duodenum & Duodenum \\
Morphology & Mild architectural distortion with polymorphic & Mild architectural distortion with polymorphic infiltrate \\
IHC/flow cytometry & Kappa-restricted plasma cells & Lambda-restricted plasma cells \\
Bone marrow & Not identified & Present with lambda-restricted plasma cells \\
Molecular studies & Positive for clonal IGH gene rearrangement & Positive for clonal IGH (bone marrow) and IGK gene \\
& & rearrangements \\
(duodenum and bone marrow)
\end{tabular}

clinical response in both cases, including one case which had incomplete response with Rituximab alone (Table 1).

\section{Discussion}

Post-transplant lymphoproliferative disorders (PTLDs) are a group of hematolymphoid diseases that develop as a consequence of immunosuppression in a recipient of a solid organ or stem cell allograft $[4,5]$. The pathogenesis of PTLD is considered to be multifactorial, but the role of EBV has been established to play a central role in driving the proliferation of EBV-infected B cells that leads to subsequent development of the lymphoproliferative disorder [6]. The incidence of PTLD depends on the type of organ transplanted, the respective intensity of immunosuppression, and the recipient's viral status (EBV and CMV seronegativity) prior to transplantation. The incidence has been steadily increasing over the years, most likely reflecting the increasing number of transplants, increasing awareness, and improved diagnostic techniques [7, 8]. Children are more prone to developing PTLDs as they are usually naive for Epstein-Barr virus (EBV) infection [9] and cytomegalovirus infection (CMV), although the effect of $\mathrm{CMV}$ is not as strong as for EBV and less consistent [10, 11]. The overall incidences for PTLD among pediatric patients are lowest in renal transplant recipients with $1-3 \%$ at 5 years post transplantation $[12,13]$ while PTLD incidence after pediatric liver transplant has an overall incidence between 5 and $10 \%$ [14-16] with the time from transplantation ranging from 1 to 84 months [16]. PTLD is most frequent in pediatric lung transplant recipients (overall PTLD incidences of approximately $15 \%)[17,18]$ and recipients of intestinal grafts (predicted incidence $20 \% \pm 5 \%$ ) [19].
The most frequent sites for PTLD in children are tonsillar/ adenoidal tissue $(34 \%)$ followed by gastrointestinal $(32 \%)$ [20]. Other organs such as the central nervous system, bone marrow, spleen, lung, small intestine, liver, and kidney may also be affected. The clinical manifestations of PTLD in children include non-specific symptoms in the form of fever, sweats, malaise, and weight loss and mass-forming lesion/s in the involved organ $[9,21]$.

The current WHO classification of tumors of hematopoietic and lymphoid tissues classifies PTLD into non-destructive PTLD, polymorphic PTLD, monomorphic PTLD, and classic Hodgkin lymphoma PTLD based on morphology, cellular composition, immunophenotype, and clonality of the cells constituting the lesion [2]. Non-destructive PTLDs are characterized by architectural preservation of the involved tissue, but in most cases, they do present as mass lesions. To this point, the three WHO-recognized subtypes of nondestructive PTLD, plasma cell hyperplasia, florid follicular hyperplasia, and infectious mononucleosis PTLD, all require the formation of a mass lesion and/or significant EBV positivity. Immunophenotypic studies show an admixture of polytypic B cells, plasma cells, and T cells without phenotypic aberrancy. Clonally rearranged IG genes are not expected, and most cases regress spontaneously with reduction in immunosuppression alone or may be successfully treated by surgical excision [22]. The histologic differential diagnosis in our cases include active EBV infection, including infectious mononucleosis-like PTLD (IM-like PTLD), which is a form of early/non-destructive PTLD lesion [2]. Both lesions show marked immunoblastic proliferation, often with foci of necrosis. The histology of our two cases is not typical of IM-like PTLD and instead shows a polymorphic lymphoid infiltrate with only rare, scattered immunoblasts and no necrosis. In addition, light chain restriction of B cells or plasma cells and 
B cell clones detected by molecular studies are rare in mononucleosis or IM-like PTLD. Oligoclonal populations may be detected on molecular studies in IM-like PTLD [23].

In contrast, polymorphic PTLDs present as mass lesions that cause architectural effacement of the involved tissue. They are composed of a heterogeneous population of immunoblasts, plasma cells, and small and intermediate sized $\mathrm{B}$ cells and T cells. Light chain class restriction in B cells is variable in polymorphic PTLDs but does not exclude the diagnosis. These PTLDs usually demonstrate clonally rearranged IG genes and usually require chemotherapy in addition to reduction in immunosuppression for successful treatment [24-26]. Our cases have features of polymorphic PTLD (morphology of infiltrate, light chain restricted plasma cells, and clonal B-cells), except that they presented without mass lesions or destructive architecture.

The gastrointestinal tract with its extensive mucosaassociated lymphoid tissue is not an unexpected site for PTLD. However, isolated PTLD of the GI tract is rare. There is also limited literature regarding the pathologic findings of pediatric GI PTLD. An early study by Nalesnik [27] reported 12 cases of GI PTLD with histologic appearance ranging from polymorphic to monomorphic and some showing clonal B cells in a non-clonal background. Cao et al. [28] subsequently reported that at 1-year follow-up after liver transplant, $31 \%$ of children developed symptomatic EBV infections, and $12 \%$ affected the GI tract. Of the 2 patients in their cohort with biopsy-proven GI PTLD, endoscopy revealed ulceration and nodularity of the GI tract. Younes et al. [29] reported 9 cases of pediatric GI PTLD post liver transplant, with majority occurring in children younger than 5 years old. The endoscopy findings range from almost normal appearing mucosa to erythematous nodularity to ulceration and perforations. O'Connor et al. [30] described 6 pediatric post liver transplant cases who presented with nonspecific GI symptoms with endoscopy revealing rubbery, raised, and ulcerated lesions which were histologically confirmed to be PTLD. The colon and stomach were the most common sites involved. Two additional pediatric case reports describe GI bleeding as the presenting symptom with endoscopic findings of ulcerations in the small intestine that were confirmed histologically as PTLD [31, 32]. In a retrospective study involving 34 patients with GI PTLD conducted by Dziegielewski et al. [33], 15 (44\%) patients had monomorphic disease, 12 (35\%) patients had polymorphic disease, $6(18 \%)$ had early lesions, and $1(3 \%)$ patient had mixed monomorphic and polymorphic. The endoscopic findings on the cases are not reported in the study. Majority of patients presented with non-specific GI symptoms, and association with EBV was identified in $65 \%$ cases, and $53 \%$ cases developed GI PTLD in the first 2 years post-transplant. EBV-negative cases appeared to have a significantly later onset of GI PTLD (median 68 months) compared to EBV positive cases.

We present two unusual cases of pediatric gastrointestinal (GI) PTLDs with pathologic features overlapping between non-destructive and polymorphic categories. Grossly and/or histologically, these cases show no mass lesions or significant architectural effacement as required for polymorphic PTLD and show evidence of clonal plasma cells and/or B cells that are not typical for the 3 recognized WHO subtypes of nondestructive PTLD. Both cases were identified on random GI biopsies that were taken due to non-specific gastrointestinal symptoms (diarrhea, abdominal pain, and food intolerance) in patients who also had hypoalbuminemia, EBV viremia, cytopenias, and in one case ascites. Both cases showed response to a combination regimen of cyclophosphamide, steroids and rituximab while one case showed incomplete response to an initial trial of rituximab alone.

One potential limitation of this conclusion is that it is difficult to entirely exclude the possibility of a "mass-forming" or other lesion with architectural effacement on histology that could be present in the portions of small intestine that could not be visualized via standard endoscopy procedures. Even if a non-visualized mass lesion is present, random GI biopsies may still be useful to diagnose PTLD in these patients.

\section{Conclusion}

These cases illustrate that some post-transplant EBV-related lesions may not fit cleanly within our current WHO PTLD categories, and clinicopathologic correlation is necessary to determine appropriate therapy. Pediatric GI PTLD can present within 1 year of transplant with vague abdominal symptoms, cytopenia, and hypoalbuminemia, without mass lesions. A high level of suspicion with random GI biopsies is recommended. Since these patients have no mass lesions, relief of GI symptoms, EBV viral load, and improvement in cytopenia and serum albumin levels may be used to monitor response to therapy.

\section{Compliance with ethical standards}

Conflict of interest The authors declare that they have conflicts of interest.

\section{References}

1. Clarke CA, Morton LM, Lynch C, Pfeiffer RM, Hall EC, Gibson TM, Weisenburger DD, Martínez-Maza O, Hussain SK, Yang J, Chang ET, Engels EA (2013) Risk of lymphoma subtypes after solid organ transplantation in the United States. Br J Cancer 109(1):280-288 
2. Swerdlow SH, Webber SA, Chadburn A, Ferry JA (2017) Posttransplant lymphoproliferative disorders. In: Swerdlow SH, Campo E, Harris NL et al (eds) WHO classification of tumours of haematopoietic and lymphoid tissues, revised, 4th edn. Lyon, IARC, pp 453-462

3. Locker J, Nalesnik M (1989) Molecular genetic analysis of lymphoid tumors arising after organ transplantation. Am J Pathol 135(6):977-987

4. Kwong YL, Lam CC, Chan TM (2000) Post-transplantation lymphoproliferative disease of natural killer cell lineage: a clinicopathological and molecular analysis. Br J Haematol 110(1):197-202

5. Kumar S, Kumar D, Kingma DW, Jaffe ES (1993) Epstein-Barr virus-associated T-cell lymphoma in a renal transplant patient. Am J Surg Pathol 17(10):1046-1053

6. Capello D, Rossi D, Gaidano G (2005) Post-transplant lymphoproliferative disorders: molecular basis of disease histogenesis and pathogenesis. Hematol Oncol 23(2):61-67

7. Dharnidharka VR, Tejani AH, Ho PL, Harmon WE (2002) Posttransplant lymphoproliferative disorder in the United States: young Caucasian males are at highest risk. Am J Transplant 2(10):993998

8. Dierickx D, Habermann TM (2018) Post-transplantation lymphoproliferative disorders in adults. N Engl J Med 378(6):549-562

9. Opelz G, Döhler B (2004) Lymphomas after solid organ transplantation: a collaborative transplant study report. Am J Transplant 4(2): 222-230

10. Sampaio MS, Cho YW, Shah T, Bunnapradist S, Hutchinson IV (2012) Association of immunosuppressive maintenance regimens with posttransplant lymphoproliferative disorder in kidney transplant recipients. Transplantation. 93(1):73-81

11. Opelz G, Daniel V, Naujokat C, Döhler B (2009) Epidemiology of pretransplant $\mathrm{EBV}$ and $\mathrm{CMV}$ serostatus in relation to posttransplant non-Hodgkin lymphoma. Transplantation. 88(8):962-967

12. Boubenider S, Hiesse C, Goupy C, Kriaa F, Marchand S, Charpentier B (1997) Incidence and consequences of posttransplantation lymphoproliferative disorders. J Nephrol 10(3): 136-145

13. Maksten EF, Vase MØ, Kampmann J, d'Amore F, Møller MB, Strandhave C, Bendix K, Bistrup C, Thiesson HC, Søndergaard E, Hamilton-Dutoit S, Jespersen B (2016) Post-transplant lymphoproliferative disorder following kidney transplantation: a population-based cohort study. Transpl Int 29(4):483-493

14. D'Alessandro AM, Knechtle SJ, Chin LT et al (2007) Liver transplantation in pediatric patients: twenty years of experience at the University of Wisconsin. Pediatr Transplant 11(6):661-670

15. Jain A, Nalesnik M, Reyes J, Pokharna R, Mazariegos G, Green M, Eghtesad B, Marsh W, Cacciarelli T, Fontes P, Abu-Elmagd K, Sindhi R, Demetris J, Fung J (2002) Posttransplant lymphoproliferative disorders in liver transplantation: a 20 -year experience. Ann Surg 236(4):429-437

16. Pinho-Apezzato ML, Tannuri U, Tannuri AC et al (2010) Multiple clinical presentations of lymphoproliferative disorders in pediatric liver transplant recipients: a single-center experience. Transplant Proc 42(5): 1763-1768

17. Cohen AH, Sweet SC, Mendeloff E et al (2000) High incidence of posttransplant lymphoproliferative disease in pediatric patients with cystic fibrosis. Am J Respir Crit Care Med 161(4 Pt 1):1252-1255

18. Elidemir O, Kancherla BS, Schecter MG, McKenzie ED, Morales DL, Heinle JS, Mallory GB (2009) Post-transplant lymphoproliferative disease in pediatric lung transplant recipients: recent advances in monitoring. Pediatr Transplant 13(5):606-610

19. Quintini C, Kato T, Gaynor JJ, Ueno T, Selvaggi G, Gordon P, McLaughlin G, Tompson J, Ruiz P, Tzakis A (2006) Analysis of risk factors for the development of posttransplant lymphoprolipherative disorder among 119 children who received primary intestinal transplants at a single center. Transplant Proc 38(6): $1755-1758$

20. L'Huillier AG, Dipchand AI, Ng VL, Hebert D, Avitzur Y, Solomon M, Ngan BY, Stephens D, Punnett AS, Barton M, Allen UD (2019) Posttransplant lymphoproliferative disorder in pediatric patients: survival rates according to primary sites of occurrence and a proposed clinical categorization. Am J Transplant 19(10):2764-2774

21. Allen U, Hébert D, Moore D, Dror Y, Wasfy S (2001) Canadian PTLD survey group-1998. Epstein-Barr virus-related posttransplant lymphoproliferative disease in solid organ transplant recipients, 1988-97: a Canadian multi-centre experience. Pediatr Transplant 5(3):198-203

22. Swerdlow SH, Campo E, Pileri SA, Harris NL, Stein H, Siebert R, Advani R, Ghielmini M, Salles GA, Zelenetz AD, Jaffe ES (2016) The 2016 revision of the World Health Organization classification of lymphoid neoplasms. Blood. 127(20):2375-2390

23. Lones MA, Mishalani S, Shintaku IP, Weiss LM, Nichols WS, Said JW (1995) Changes in tonsils and adenoids in children with posttransplant lymphoproliferative disorder: report of three cases with early involvement of Waldeyer's ring. Hum Pathol 26(5): $525-530$

24. Harris NL, Ferry JA, Swerdlow SH (1997) Posttransplant lymphoproliferative disorders: summary of Society for Hematopathology Workshop. Semin Diagn Pathol 14(1):8-14

25. Knowles DM, Cesarman E, Chadburn A, Frizzera G, Chen J, Rose EA, Michler RE (1995) Correlative morphologic and molecular genetic analysis demonstrates three distinct categories of posttransplantation lymphoproliferative disorders. Blood. 85(2):552-565

26. Chadburn A, Chen JM, Hsu DT, Frizzera G, Cesarman E, Garrett TJ, Mears JG, Zangwill SD, Addonizio LJ, Michler RE, Knowles DM (1998) The morphologic and molecular genetic categories of posttransplantation lymphoproliferative disorders are clinically relevant. Cancer. 82(10):1978-1987

27. Nalesnik MA (1990) Involvement of the gastrointestinal tract by Epstein-Barr virus-associated posttransplant lymphoproliferative disorders. Am J Surg Pathol 14(Suppl 1):92-100

28. Cao S, Cox K, Esquivel C et al (1998) Posttransplant lymphoproliferative disorders and gastrointestinal manifestations of EpsteinBarr virus infection in children following liver transplantation. Transplantation. 66(7):851-856

29. Younes BS, Ament ME, McDiarmid SV, Martin MG, Vargas JH (1999) The involvement of the gastrointestinal tract in posttransplant lymphoproliferative disease in pediatric liver transplantation. J Pediatr Gastroenterol Nutr 28(4):380-385

30. O'Connor JA, Cogley C, Burton M, Lancaster-Weiss K, Cordle RA (2000) Posttransplantation lymphoproliferative disorder: endoscopic findings. J Pediatr Gastroenterol Nutr 31(4):458-461

31. Ho EY, George V, McCracken M, Ostroff JW (2014) A 13 year-old boy with post-transplantation lymphoproliferative disorder presenting with obscure gastrointestinal bleeding: a case report. F1000Res 3:88 Published 2014 Apr 7

32. Sebire NJ, Malone M, Risdon RA, Ramsay AD (2005) EpsteinBarr virus-associated lymphoproliferative disorder presenting as apparently isolated gastrointestinal lesions in childhood. Pediatr Dev Pathol 8(1):88-91

33. Dziegielewski C, Contreras R, Weitzman S, Gerstle JT (2018) Pediatric gastrointestinal posttransplant lymphoproliferative disorder: incidence, clinical characteristics, and impact of major surgical interventions upon overall survival. J Pediatr Hematol Oncol 40(6): $438-444$

Publisher's note Springer Nature remains neutral with regard to jurisdictional claims in published maps and institutional affiliations. 